\title{
ANALISA SISTEM SINKRONISASI FILE DATABASE PADA MULTI-SERVER MENGGUNAKAN AGLETS
}

\author{
Wisnu Maruta ${ }^{\text {a) }}$, Wisnu Broto ${ }^{\text {b) }}$ \\ Jurusan Teknik Elektro, Universitas Pancasila \\ Jl. Raya Agung, Jagakarsa, Kota Jakarta Selatan, Daerah Khusu Ibukota Jakarta \\ Email: ${ }^{\text {a)}}$ wisnu.maruta99@gmail.com, ${ }^{\text {b) }}$ wisnu.agni@gmail.com
}

\begin{abstract}
Abstrak
Perkembangan teknologi perangkat keras komputer yang begitu pesat telah mengubah paradigma pengembangan software agar mampu berjalan dalam berbagai platform sistem operasi. Sistem berbasis web server merupakan salah satu aplikasi komputer yang membutuhkan kompatilitas yang tinggi sehingga komputer dengan teknologi hardware dan software yang berbeda dapat berkomunikasi dengan baik. Berbagai penyebab memungkinkan terjadinya masalah pada server tunggal, sehingga perlu dipertimbangkan untuk menggunakan backup server. Backup server berisi data yang sama dengan data dari server utama. Hal tersebut dapat dilakukan dengan cara mensinkronkan file secara berkala. Dalam studi ini, sinkronisasi file diwujudkan menggunakan Aglets. Aglets merupakan framework mobile agent dengan kemampuan berpindah dan melakukan tugas sesuai keinginan. Hasil pengujian menunjukkan sinkronisasi berjalan dengan baik menggunakan prinsip mobile agent. Untuk memaksimalkan kerja sinkronisasi, sebaiknya dua server diletakkan pada satu jaringan untuk mendapatkan kecepatan sinkronisasi yang maksimal. Sinkronisasi file menggunakan data sampai dengan 1200 file berhasil dilakukan.
\end{abstract}

Kata-kata Kunci: Platform, Backup server, Mobile Agent, Aglets, Sinkronisasi file

\begin{abstract}
The rapid development of computer hardware technology has changed the paradigm of software to be able to run on various operating system platform. Web server-based system is one of the computer applications that require jigh compatibility so that compiters with different hardware and software technologies can communicate well. Various causes allow for the occurrence of the problems on a single server, so consideration should be given to using a server backup. The backup server contains the same data as the data from the main server. It can be done by synchronizing files periodically. In this study, file synchronization is realized by using Aglets. Aglets is a mobile agent framework with ability to nove and do tasks as desired. The results of the test shows that synchronization works well using mobile agent principle. To maximize synchronization work, we recommend two servers to be placed on one network to get the maximum synchronization speed. File synchronization using data up to 1200 files successfully done.
\end{abstract}

Keywords : Platform, Backup server, Mobile Agent, Synchronization file 


\section{PENDAHULUAN}

Dalam membangun suatu layanan publik, kita akan selalu bertemu atau berhubungan dengan yang namanya server. Server merupakan inti yang sangat penting, misalnya dalam dunia pekerjaan. Dan begitu banyak data yang akan di simpan, sehingga tidak hanya menggunakan satu server saja. Dengan berbagai penyebab yang memungkinkan terjadinya masalah pada suatu layanan atau server tersebut. Maka perlu di pertimbangkan untuk menggunakan backup server. Backup server berisi tentang data yang sama dengan data dari server utama dan selalu terbaru atau up-to-date. Sehingga apabila mengalami atau terjadinya masalah pada server utama, masih memiliki data cadangan terbaru yang siap untuk digunakan sesuai dengan kebutuhan user. Serta mekanisme penyamaan data ( data mirroring) ini membutuhkan aplikasi sendiri, yaitu sinkronisasi file. Sinkronisasi file ini perlu dijalankan secara berkala agar memilki data cadangan yang terbaru pada backup server.

Aglets merupakan suatu Teknologi Mobile Agent yang memiliki kemampuan berpindah dari satu host ke host lainnya. Ketika berpindah, state program ini disimpan, dibawa ke host selanjutnya dan berjalan sebagai proses yang normal. Dan dalam hal ini digunakan sebagai media untuk melakukan sinkronisasi file antara dua server.

Beberapa riset yang telah dilakukan sebelumnya mengenai teknologi Mobile Agent seperti Analisa Sistem Keamanan Intrusion Detection System (IDS), Firewall System, Database System dan Monitoring System Menggunakan Agent Bergerak oleh Bambang Sugiantoro [1], kemudian Mobile Agent for Networked Electronic Trading oleh Prithviraj Dasgupta dkk [2] adalah contoh penerapan Mobile Agent Aglets pada e-commerce. Contoh lainnya adalah penggunaan Aglets dan JACOB untuk polling halaman web yang dibuat oleh Intan dan Joko [3] dimana agent merekam URL yang berguna (useful) bagi pengguna dan membagikannya kepada pengguna lain. Ada juga yang menggunakan agent untuk mendeteksi suatu ancaman tentang keamanan pada jaringan komputer yang dilakukan oleh Anggar Djiwandono.

\section{METODE PENELITIAN}

Aplikasi sinkronisasi file ini merupakan aplikasi yang bekerja dengan cara menyamakan isi dari direktori yang telah ditentukan pada Server A dengan isi direktori yang telah ditentukan pada Server B. Server A bertindak sebagai server utama sedangkan Server B sebagai backup server. Graphical User Interface (GUI) dari aplikasi ini memiliki satu tampilan dari SyncAgent. Sedangkan untuk agent yang lain tidak ada. Kemudian untuk notifikasi ditampilkan di command line. Selain GUI dari SyncAgent ada juga Auto Index PHP Script yang digunakan memudahkan user untuk melihat daftar file yang disinkronkan. Auto Index PHP Script merupakan sistem manajemen konten (CMS) open source berbasis web yang dikembangkan menggunakan PHP oleh Justin Hagstorm. CMS ini digunakan untuk mengindeks file dan juga dapat mengunduhnya sesuai keinginan 


\section{Pemodelan Arsitektur}

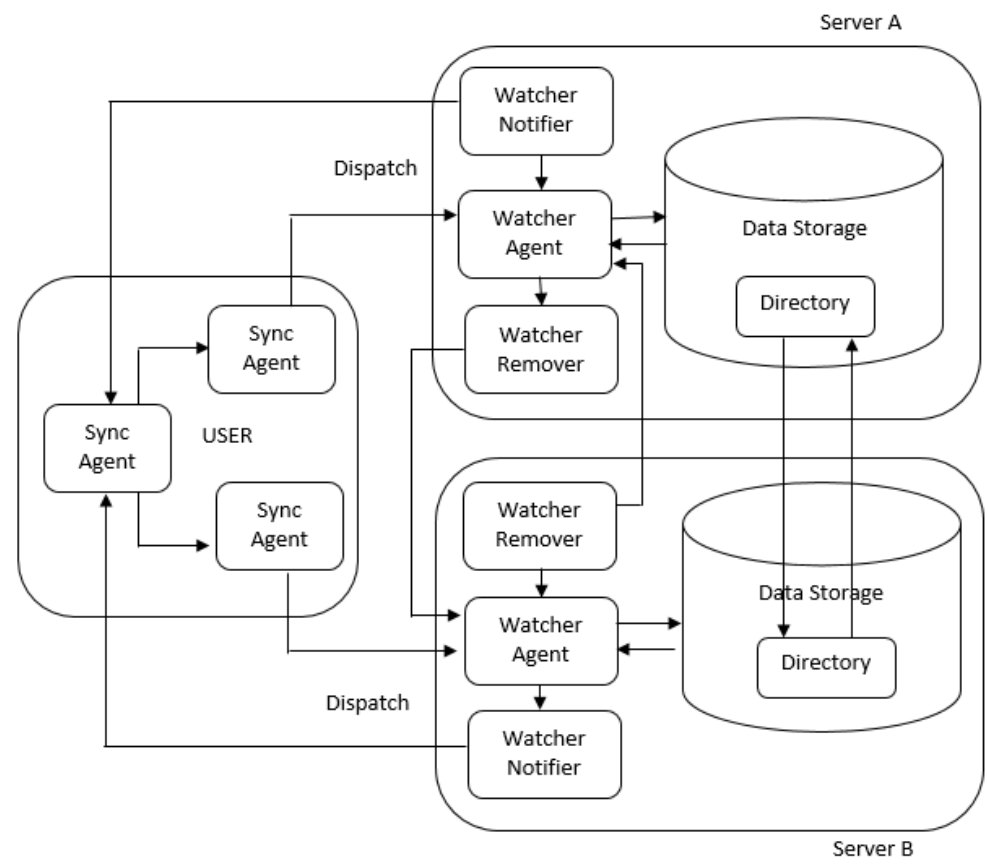

GAMBAR 1. Arsitektur aplikasi sinkronisasi file

Arsitektur dari aplikasi ini dapat dilihat pada Gambar 1. Di Gambar 1 diperlihatkan bagaimana agent dibuat, dikirim kemudian bekerja sama untuk mensinkronkan file. Pada User, SyncAgent membuat dua WatcherAgent kemudian masing-masing dikirimkan ke Server A dan Server B. Pada Server A dan Server B masing-masing WatcherAgent mengakses data yang berada di dalam direktori target kemudian saling bekerja sama untuk mensinkronkan data. Apabila WatcherAgent mendeteksi ada file yang terhapus, maka WatcherAgent akan mengirimkan WatcherRemover kepada WatcherAgent lainnya. Informasi selama proses sinkronisasi akan dikirimkan oleh WatcherNotifier.

\section{Pemodelan UML}

Activity Diagram pada Gambar 2 menunjukkan dimana proses awal sampai akhir yang harus dilakukan untuk menjalankan aplikasi sinkronisasi file melalui Tahiti Server. Berdasarkan Gambar 2 dapat dijelaskan sebagai berikut. Aplikasi dimulai dengan cara menjalankan Aglets. Kemudian membuat SyncAgent.

Setelah SyncAgent dibuat maka user perlu mengisi form dengan benar. Apabila ada kesalahan user harus membenarkannya agar SyncAgent dapat berjalan. Apabila sudah benar WatcherAgent akan dikirim untuk mengecek apakah direktori untuk sinkronisasi ada. Apabila direktori tidak ditemukan maka sinkronisasi tidak dapat berlangsung. Apabila direktori ada maka proses sinkronisasi akan berlangsung. Apabila sinkronisasi gagal maka sinkronisasi akan berhenti. Apabila kerja SyncAgent dihentikan maka sinkronisasi juga akan berhenti. 


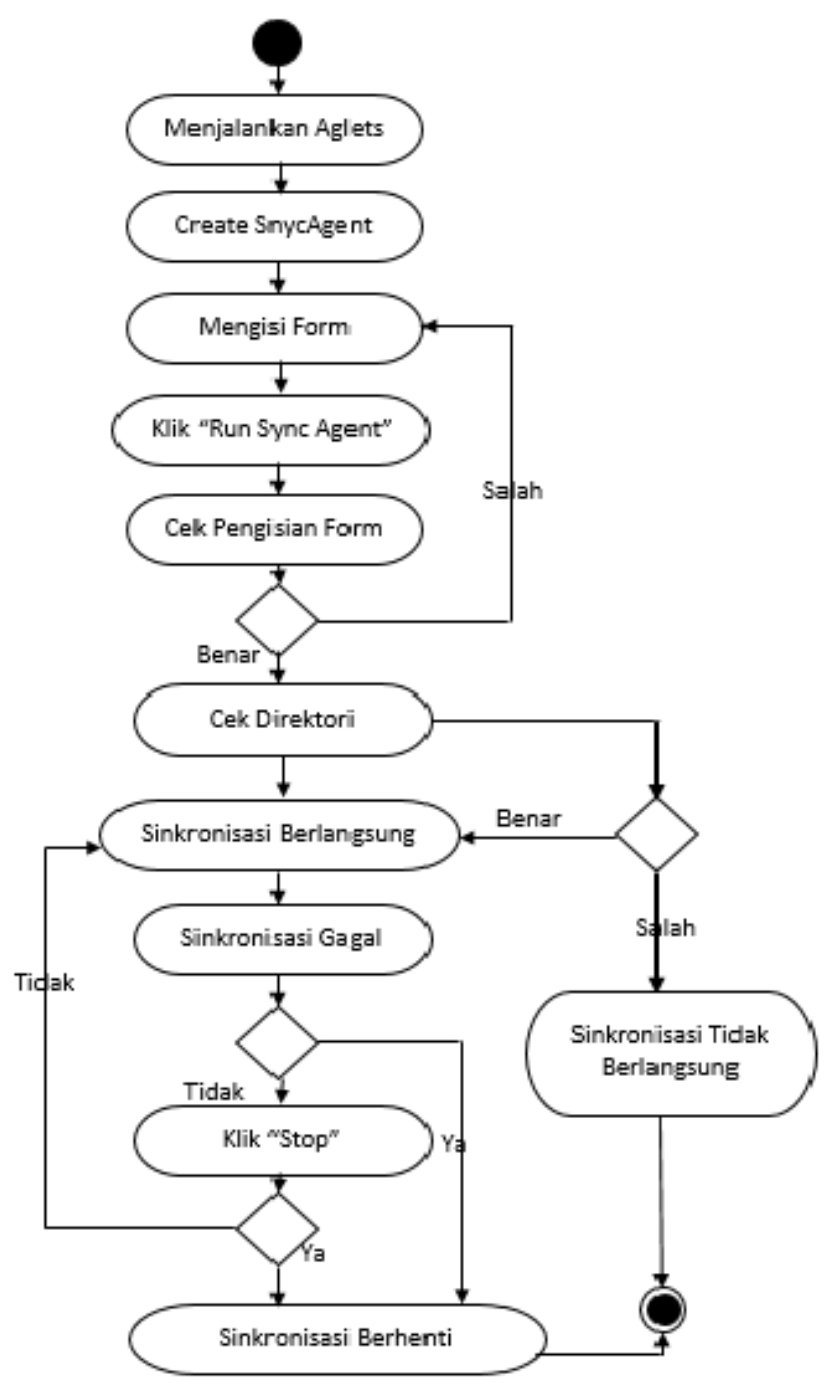

GAMBAR 2. Activity Diagram aplikasi sinkronisasi file

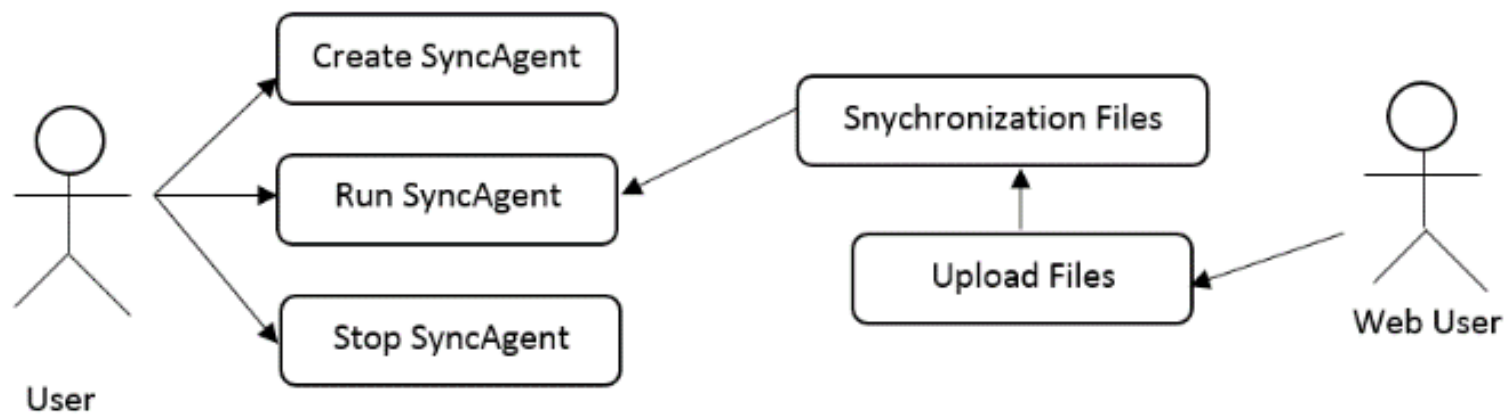

GAMBAR 3. Use Case Diagram aplikasi sinkronisasi file 
TABEL 1. Identifikasi Use Case

\begin{tabular}{|l|l|l|l|}
\hline No & Aktor & Use Case & Deskripsi \\
\hline 1 & User & $\begin{array}{l}\text { Create } \\
\text { SyncAgent }\end{array}$ & $\begin{array}{l}\text { Pengguna Membuat (create agent) } \\
\text { SyncAgent melalui Window tahiti : } \\
\text { The Aglets Viewer yang dimiliki } \\
\text { Aglets. }\end{array}$ \\
\hline 2 & User & Run SyncAgent & $\begin{array}{l}\text { Pengguna menjalankan SyncAgent } \\
\text { untuk mengirimkan WatcherAgent } \\
\text { ke server agar dapat melakukan } \\
\text { sinkronisasi file. }\end{array}$ \\
\hline 3 & User & Stop SyncAgent & $\begin{array}{l}\text { Pengguna menghentikan sinkronisasi } \\
\text { file dengan cara membuang } \\
\text { (dispose) WatcherAgent. }\end{array}$ \\
\hline 4 & - & $\begin{array}{l}\text { Synchronizing } \\
\text { files }\end{array}$ & $\begin{array}{l}\text { Sinkronisasi file berjalan pada server. } \\
\text { Sinkronisasi dijalankan oleh } \\
\text { WatcherAgent. }\end{array}$ \\
\hline 5 & $\begin{array}{l}\text { Web } \\
\text { User }\end{array}$ & Upload Files & $\begin{array}{l}\text { Pengguna Web melakukan } \\
\text { pengunggahan file pada server. }\end{array}$ \\
\hline
\end{tabular}

Use Case diagram dari aplikasi ini ditunjukkan pada Gambar 4 sedangkan deskripsi use case dan aktoraktor yang terlibat didalamnya, dapat dilihat pada Tabel 1.

\section{HASIL DAN PEMBAHASAN}

\section{Pengujian Program}

Pada tahap pengujian ini dilakukan untuk mengetahui cara penggunaan program, kecepatan program dan seberapa besar kemampuan program untuk melakukan sinkronisasi. Serta menganalisa kerja program dalam melakukan sinkronisasi. Pengujian program ini dilakukan dengan menggunakan dua host dimana kedua host akan menjalankan sinkronisasi. Selain melakukan sinkronisasi, satu dari dua host tersebut akan bertindak sebagai user yang menjalankan SyncAgent.

\section{SyncAgent}

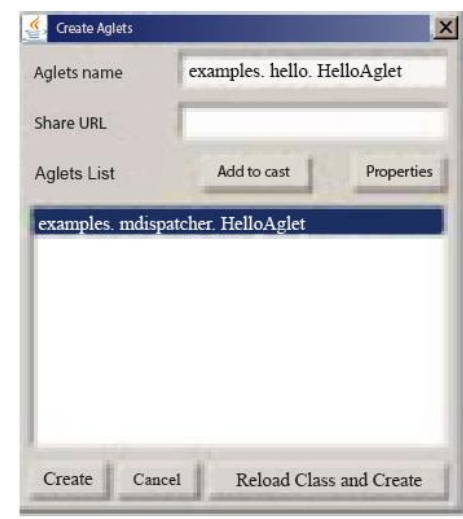

GAMBAR 4. Create Aglets

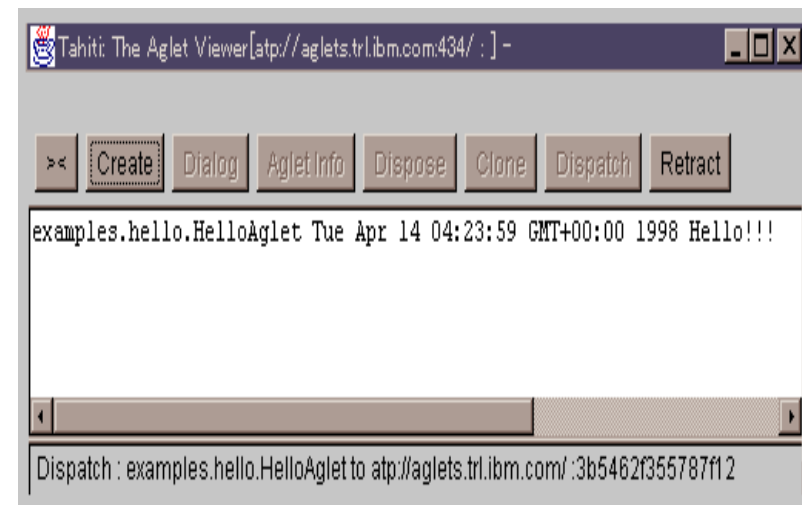

GAMBAR 5. Tampilan Tahiti Server

Pertama yang harus dilakukan untuk menjalankan SyncAgent adalah menjalankan Aglets 2.02 di kedua host. Tampilan utama dari Aglets adalah Tahiti Server. Tahiti Server ditunjukkan pada Gambar 5. Kemudian membuat (create) SyncAgent dengan cara klik tombol "Create" pada Tahiti. Kemudian memilih SyncAgent pada window Create Agent. Lalu klik tombol "Create". Gambar 4 menunjukkan tampilan window Create Agent. 


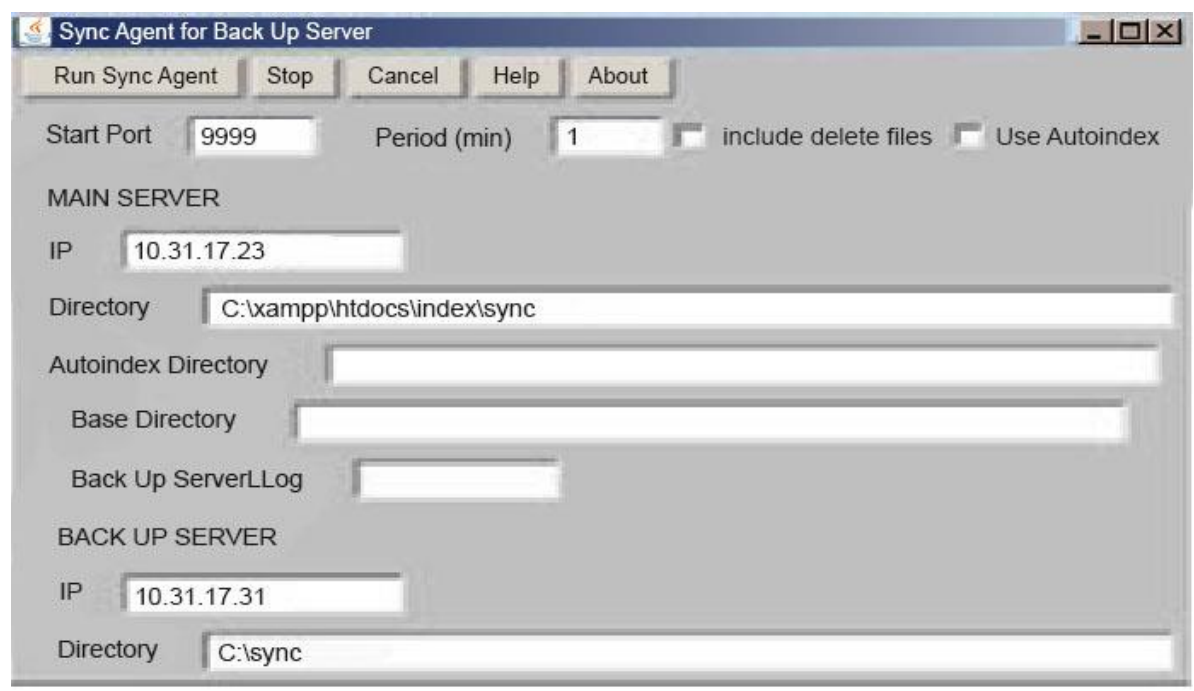

GAMBAR 6. GUI SyncAgent

Setelah SyncAgent sudah dibuat maka akan muncul tampilan yang ditunjukkan pada Gambar 6 . Informasi dari host pertama diisikan pada form MAIN SERVER, sedangkan informasi dari host kedua pada form BACKUP SERVER. Form pada AutoIndex Directory, Base Directory dan Backup Server Log diisi sama dengan pengaturan pada AutoIndex PHP Script apabila Use AutoIndex diaktifkan. Setelah semua form diisi, klik tombol "Run Sync Agent" untuk menjalankan SyncAgent dan klik tombol "Stop" untuk menghentikan kerja SyncAgent. Selanjutnya masuk ke halaman web dari AutoIndex PHP Script. Kemudian login menggunakan akun Admin. Pada menu admin klik "Reconfigure Script" kemudian isi form pada "base_dir" dan "backup_log". "base_dir" menunjukkan letak direktori dasar yang akan ditampilkan sedangkan "backup_log" untuk menampilkan kolom Backup Information.

\begin{tabular}{|c|c|c|c|c|}
\hline \multicolumn{5}{|l|}{ Index_of/File/ } \\
\hline File & Download & Size & Modified & Back Up Files \\
\hline [BAGAS31] KMSpico 10.2.0 Final Activator.zip & 1 & $8.9 \mathrm{MB}$ & 2017-Jan-02 & 2017-Jan-02 \\
\hline ASUS_TOOI_WW_4_3_5_UpdateLauncher.zip & 2 & $7.6 \mathrm{MB}$ & 2017-Jan-02 & 2017-Jan-02 \\
\hline ACS6MCAP-CZv6.03 - SSSL.rar & 1 & $5.6 \mathrm{MB}$ & 2017-Jan-04 & 2017-Jan-04 \\
\hline Autodesk 3ds Max 2012 English Win32-64bit & 2 & $4.9 \mathrm{MB}$ & 2017-Jan-05 & 2017-Jan-05 \\
\hline adb-setup-1.4.3(afandindo.blogspot.com).rar & 2 & $4.5 \mathrm{MB}$ & 2017-Jan-07 & 2017-Jan-07 \\
\hline python-3.5.2.exe & 1 & 4.4 MB & 2017-Jan-07 & 2017-Jan-07 \\
\hline NI Multisim \& Ultiboard (Circuit Design Suite) v13.0.iso & 1 & $3.4 \mathrm{MB}$ & 2017-Jan-08 & 2017-Jan-08 \\
\hline cz_ost_complete.zip & 1 & $8.5 \mathrm{MB}$ & 2017-Jan-09 & 2017-Jan-09 \\
\hline Input_Driver_FW20D_WN_8.1206.101.112_A00.EXE & 4 & 14.2 MB & 2017-Jan-10 & 2017-Jan-10 \\
\hline [BAGAS31] Microsoft Visual C++ Pack.rar & 4 & $15.9 \mathrm{MB}$ & 2017-Jan-12 & 2017-Jan-12 \\
\hline studio-install-windows.mp4 & 4 & $800 \mathrm{~KB}$ & 2017-Jan-12 & 2017-Jan-12 \\
\hline Total & Total : 23 & Total Sze : $78.7 \mathrm{MB}$ & & \\
\hline
\end{tabular}

GAMBAR 7. Tampilan Backup Information

Setiap informasi yang ditampilkan pada kolom Backup Information berupa tulisan last modified file dengan ketentuan sebagai berikut:

1. Berwarna abu-abu bertuliskan "not synced", artinya file belum pernah disinkronkan.

2. Berwarna hijau, artinya file sudah disinkronkan.

3. Berwarna merah, artinya file lebih baru (update) belum disinkronkan. 


\section{Optional Settings:}

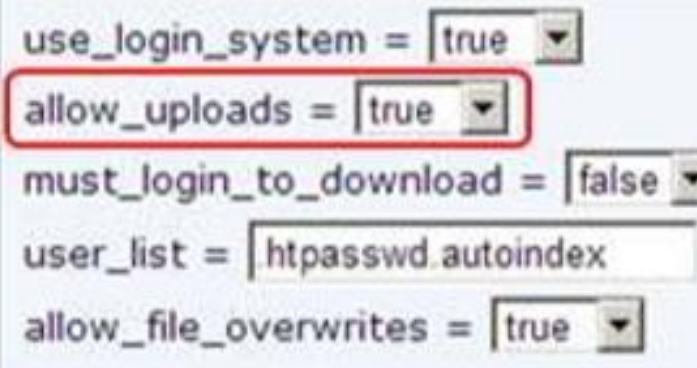

GAMBAR 8. Pengaturan pengunggahan bagi user

Ada dua cara untuk menambahkan file dan memperbarui file menggunakan SyncAgent. Pertama, salin dan tempel (copy paste) file ke direktori target. Ini bisa dilakukan secara langsung atau melalui remote. Kedua, mengunggah file melalui form upload pada halaman Admin. Cara kedua merupakan cara yang lebih mudah, karena user tidak perlu masuk ke dalam sistem hanya perlu mengakses melalui web. User yang melakukan pengunggahan tidak harus menggunakan akun Admin karena Autoindex PHP Script memberikan pengaturan pengunggahan selain Admin. Gambar menunjukkan letak pengaturan pengunggahan bagi user. Kemudian cara untuk menghapus file hanya dapat dilakukan secara langsung maupun melalui remote.

\section{Pengujian Sinkronisasi}

Pengujian dilakukan dengan memberikan variasi ukuran file dan jumlah file. Koneksi antara kedua host menggunakan kabel UTP cross secara point-to-point. Bertujuan untuk mengetahui waktu yang di butuhkan SyncAgent untuk menjalankan sinkronisasi dalam satu kali siklus. Kondisi dan kebutuhan pengujian sinkronisasi dapat dilihat pada Tabel 2.

TABEL 2. Kondisi dan Kebutuhan Pengujian

\begin{tabular}{|c|c|c|c|c|}
\hline \multirow{2}{*}{ Host } & \multirow{2}{*}{ Server } & \multirow{2}{*}{ Alamat IP } & \multicolumn{2}{|c|}{ Spesifikasi Host } \\
\hline & & & Perangkat Keras & Perangkat Lunak \\
\hline $\begin{array}{l}\text { Host } 1 \\
\text { (User) }\end{array}$ & $\begin{array}{l}\text { Main } \\
\text { Server }\end{array}$ & 10.31.17.23 & $\begin{array}{l}\text { - Intel Core i3 } \\
\text { - Harddisk } 300 \text { GB } \\
\text { - } \text { RAM } 4 \text { GB } \\
\text { - Realtek PCI, GBE } \\
\text { Family Controller } \\
\end{array}$ & $\begin{array}{l}\text { - Windows } 7 \\
\text { - Java } 7 \\
\text { - Aglets } 2.02\end{array}$ \\
\hline Host 2 & $\begin{array}{l}\text { Backup } \\
\text { Server }\end{array}$ & 10.31.36.31 & $\begin{array}{l}\text { - } \text { AMD C-50 } 1 \text { GHZ } \\
\text { - Harddisk } 500 \text { GB } \\
\text { - } \text { RAM } 2 \text { GB } \\
\text { - Atheron ARS } 152 / 81.58 \\
\text { PCl-E Fast Ethernet }\end{array}$ & $\begin{array}{l}\text { - Windows } 7 \\
\text { - Java } 7 \\
\text { - Aglets } 2.02\end{array}$ \\
\hline
\end{tabular}




\section{Pengujian dengan Variasi Ukuran File}

TABEL 3. Pengujian Sinkronisasi dengan variasi besar file.

\begin{tabular}{|c|c|c|c|c|c|}
\hline \multirow{2}{*}{ No. } & \multirow{2}{*}{$\begin{array}{l}\text { Besar File } \\
\text { (MB) }\end{array}$} & \multicolumn{2}{|c|}{$\begin{array}{l}\text { Waktu Sinkronisasi } \\
\text { WatcherAgent (ms) }\end{array}$} & \multirow{2}{*}{$\begin{array}{l}\text { Waktu Rata - Rata } \\
\text { Sinkronisasi (ms) }\end{array}$} & \multirow{2}{*}{$\begin{array}{l}\text { Kecepatan Rata } \\
\text { - Rata (MB/s) }\end{array}$} \\
\hline & & 1 & 2 & & \\
\hline 1 & 5,2 & 2350 & 2396 & 2373 & 2,541089 \\
\hline 2 & 19,6 & 5604 & 5688 & 5672 & 4,372845 \\
\hline 3 & 30 & 7868 & 7878 & 7890 & 4,396745 \\
\hline 4 & 42,3 & 8891 & 8876 & 8890 & 4,076897 \\
\hline 5 & 50,5 & 1234 & 1255 & 1298 & 4,291181 \\
\hline 6 & 56 & 13218 & 13452 & 13776 & 3,890011 \\
\hline 7 & 72,2 & 15457 & 15099 & 15432 & 4,679120 \\
\hline 8 & 75 & 15533 & 15132 & 15554 & 3,488901 \\
\hline 9 & 99,7 & 19902 & 19456 & 19789 & 4,690122 \\
\hline 10 & 101 & 22345 & 22333 & 22378 & 4,234442 \\
\hline 11 & 115 & 24889 & 24987 & 24211,8 & 4,543251 \\
\hline 12 & 126 & 25508 & 25332 & 25890 & 4,334521 \\
\hline 13 & 134 & 29978 & 29544 & 29876 & 4,176123 \\
\hline 14 & 150 & 32099 & 32876 & 32778 & 4,231333 \\
\hline
\end{tabular}

Pengujian ini dilakukan dengan cara memberikan file baru secara berkala dengan kelipatan 5,2 MB. Kemudian mencatat waktu yang dibutuhkan program untuk menyelesaikan sinkronisasi pada kedua WatcherAgent. Hasil pengujian dapat dilihat pada Tabel 3.

Berdasarkan Tabel 3 dapat dilihat bahwa semakin besar file maka semakin besar pula waktu yang dibutuhkan untuk melakukan sinkronisasi. Selain itu didapatkan kecepatan sinkronisasi file dengan kecepatan minimum sekitar 2,54 MB/s ,kecepatan maksimum sekitar 4,69 MB/s dan kecepatan rata-rata sekitar 4,33 MB/s. Kecepatan sinkronisasi yang tidak tetap tersebut terjadi karena aplikasi dibuat menggunakan koneksi stream menggunakan protokol TCP. Selama proses pengiriman file dimungkinkan terjadi paket data hilang, rusak ataupun kesalahan pengiriman sehingga paket data yang hilang tersebut perlu dikirimkan ulang. Ini merupakan karakteristik dari protokol TCP. Selain itu waktu rata-rata yang hampir sama dapat dilihat pada data nomor 7 dan 8, walaupun kecepatan rata rata transfer data tidaklah sama. Hal ini disebabkan karena sinkronisasi dilakukan pada jaringan Internet aktif, sehingga waktu yang dibutuhkan untuk melakukan sinkronisasi dimungkinkan bertambah atau berkurang sesuai arus data yang melewati jaringan. 


\section{Pengujian dengan Variasi Jumlah File}

TABEL 4. Pengujian Sinkronisasi dengan variasi jumlah file.

\begin{tabular}{|c|c|c|c|c|c|}
\hline \multirow{2}{*}{ No. } & \multirow{2}{*}{$\begin{array}{c}\text { Jumlah File } \\
(1 \text { file }=5,2 \\
\text { MB })\end{array}$} & \multicolumn{2}{|c|}{$\begin{array}{l}\text { Waktu Sinkronisasi } \\
\text { WatcherAgent (ms) }\end{array}$} & \multirow{2}{*}{$\begin{array}{l}\text { Waktu Rata-Rata } \\
\text { Sinkronisasi (ms) }\end{array}$} & \multirow{2}{*}{$\begin{array}{l}\text { Kecepatan Rata-Rata } \\
\text { (MB/s) }\end{array}$} \\
\hline & & 1 & 2 & & \\
\hline 1 & 1 & 1350 & 1367 & 1369 & 2,541089 \\
\hline 2 & 2 & 2567 & 2546 & 2534 & 4,372845 \\
\hline 3 & 3 & 3455 & 3425 & 3477 & 4,396745 \\
\hline 4 & 4 & 4567 & 4599 & 4578 & 5,076897 \\
\hline 5 & 5 & 6778 & 6755 & 6758 & 4,291181 \\
\hline 6 & 6 & 7455 & 7456 & 7432 & 6,890011 \\
\hline 7 & 7 & 8767 & 8777 & 8798 & 8,679120 \\
\hline 8 & 8 & 8098 & 8066 & 8023 & 7,488901 \\
\hline 9 & 9 & 8976 & 8958 & 8934 & 7,690122 \\
\hline 10 & 10 & 1265 & 1277 & 1234 & 9,234442 \\
\hline 11 & 11 & 1345 & 1344 & 1324 & 8,543251 \\
\hline 12 & 12 & 1478 & 1453 & 1467 & 9,334521 \\
\hline
\end{tabular}

Pengujian ini dilakukan dengan cara memberikan file baru dengan jumlah tertentu dengan ukuran yang sama yaitu 5,2 MB. Kemudian mencatat waktu yang dibutuhkan program untuk menyelesaikan sinkronisasi pada kedua WatcherAgent. Berdasarkan Tabel 4 dapat dilihat bahwa semakin banyak jumlah file (dengan ukuran masing-masing sama) semakin besar pula waktu yang dibutuhkan untuk melakukan sinkronisasi. Ini terbukti dari nilai waktu rata-rata sinkronisasi yang cenderung bertambah dari $2548 \mathrm{~ms}$ sampai 1478 ms. Namun dari hasil perhitungan kecepatan sinkronisasi didapatkan semakin banyak jumlah file maka kecepatan sinkronisasi cenderung naik. Ini dikarenakan proses sinkronisasi dijalankan secara multithreading. Setiap file disinkronkan oleh satu thread. Semakin banyak file semakin banyak thread dibuat dan thread-thread tersebut dieksekusi secara bersamaan. Meski demikian, penurunan kecepatan sinkronisasi terjadi pada data nomor 5, 8 dan 9. Ini dikarenakan lalu lintas data pada jaringan mempengaruhi latency pada koneksi stream masing-masing thread. Latency merupakan waktu yang dibutuhkan untuk menjalin koneksi antara kedua host. Apabila arus data pada jaringan meningkat maka semakin lama waktu yang dibutuhkan untuk menjalin koneksi antara kedua host dan ini berakibat pula pada waktu ratarata sinkronisasi yang semakin lama. 


\section{Pengujian dengan Variasi Ukuran dan Jumlah File}

TABEL 5. Pengujian Sinkronisasi dengan variasi ukuran dan jumlah file..

\begin{tabular}{|c|c|c|c|c|c|c|c|}
\hline \multirow{2}{*}{ No. } & \multirow{2}{*}{$\begin{array}{c}\text { Jumlah } \\
\text { File }\end{array}$} & $\begin{array}{c}\text { Ukuran } \\
\text { File (MB) }\end{array}$ & \multicolumn{2}{|c|}{$\begin{array}{l}\text { Waktu Sinkronisasi } \\
\text { WatcherAgent (ms) }\end{array}$} & $\begin{array}{c}\text { Waktu Rata - } \\
\text { Rata } \\
\text { Sinkronisasi } \\
\text { (ms) }\end{array}$ & $\begin{array}{c}\text { Kecepatan } \\
\text { Rata - Rata } \\
\text { (MB/s) }\end{array}$ & Keterangan \\
\hline 1 & 100 & 222 & 29087 & 29542 & 29590 & 6,541089 & Berhasil \\
\hline 2 & 200 & 435 & 53452 & 53342 & 53456 & 7,372845 & Berhasil \\
\hline 3 & 300 & 667 & 64431 & 64433 & 67689 & 8,396745 & Berhasil \\
\hline 4 & 400 & 978 & 89765 & 89092 & 83457 & 8,076897 & Berhasil \\
\hline 5 & 500 & 1146 & 111233 & 111453 & 111233,2 & 8,291181 & Berhasil \\
\hline 6 & 600 & 13345,70 & 152345 & 152413 & 153451 & 7,890011 & Berhasil \\
\hline 7 & 700 & 17889,72 & 178921 & 173312 & 173907 & 7,679120 & Berhasil \\
\hline 8 & 800 & 19001,88 & 189763 & 183421 & 183566 & 8,488901 & Berhasil \\
\hline 9 & 900 & 20987,90 & 257778 & 257432 & 258970 & 8,690122 & Berhasil \\
\hline 10 & 1000 & 22345,81 & 278342 & 274258 & 273456 & 8,234442 & Berhasil \\
\hline 11 & 1100 & 25637,88 & 312631 & 317008 & 316095 & 8,543251 & Berhasil \\
\hline 12 & 1200 & 28990,61 & 339290 & 3392934 & 339298,6 & 8,334521 & Berhasil \\
\hline
\end{tabular}

\section{KESIMPULAN}

Pengujian ini dilakukan dengan cara memberikan file baru dengan jumlah tertentu dengan ukuran yang berbeda-beda. Ukuran tersebut dibuat secara acak menggunakan program dengan range antara 1 byte sampai dengan $20 \mathrm{MB}$. Kemudian mencatat waktu yang dibutuhkan program untuk menyelesaikan sinkronisasi pada kedua WatcherAgent. Berdasarkan pengujian pada Tabel 5 dapat dijelaskan sebagai berikut. Selain itu didapatkan kecepatan yang bervariasi pula dengan kecepatan minimum sekitar 7,37 $\mathrm{MB} / \mathrm{s}$, kecepatan maksimum sekitar 8,69 MB/s dan kecepatan rata-rata sinkronisasi file adalah 8,32 MB/s. Namun pada data nomor 2, 6 dan 7 terjadi penurunan sekitar $1 \mathrm{MB} / \mathrm{s}$ terhadap data lainnya. Hal ini dikarenakan lalu lintas data pada jaringan yang terkadang tinggi memperlambat komunikasi yang dibuat secara multithreading. Thread maksimal yang dibuat pada aplikasi ini jumlahnya adalah 25. Setiap mencapai 25 thread maka proses sinkronisasi berhenti pada selang waktu tertentu untuk menunggu semua trhead selesai berjalan. Kecepatan rata - rata saat melakukan sinkronisasi file adalah 8,32 MB/s. Auto Index PHP Script dapat menampilkan informasi sinkronisasi file pada kolom Backup Informastion, namun karena tidak ada (fitur) batasan jumlah file yang ditampilkan pada satu halaman, Auto Index PHP Script hanya dapat menampilkan 1400 file dan atau folder dalam satu halaman. Sinkronisasi file akan lebih bermanfaat apabila ditambahkan fitur pelaporan sinkronisasi via email ataupun SMS gateway. Agar kerja Aglets lebih maksimal dan keamanannya lebih baik lagi, karena banyak nya user yang tidak menyimpan file dalam bentuk yang hanya memakai satu server maupun dua server saja. 


\section{UCAPAN TERIMAKASIH}

Terimakasih banyak kepada pembimbing saya, Wisnu Broto, ST.MT yang telah membantu selama membuat serta mengerjakan makalah full paper dan kepada Prodi Elektro Fakultas Teknik Universitas Pancasila, karena telah memberikan kesempatan untuk mengikuti Seminar Nasional Fisika UNJ 2017 dan menjadi pemakalah serta membimbing untuk perisapan dalam Seminar Nasional Fisika 2017.

\section{REFERENSI}

[1] Yudianto, Scifo Anggi, Somantri, M., dan Isnanto, R. Rizal, "Perancangan dan Pembuatan Perangkat Lunak Berbasis Mobile Agent untuk Pencarian Buku", Universitas Diponegoro, Semarang, 2011.

[2] Available: http://ojs.unud.ac.id/index.php/lontar/article/view/23072 [Online]

[3] Available: http://mydjiwandono.blogspot.co.id/2013/01/jurnal-aplikasi-mobile-agent-untuk.html [Online]

[4] S. Adang, M. Adityo, B. Julius, "SISTEM MOBILE AGENT DALAM KOMPUTASI GRID" Proceeding, Seminar Ilmiah Nasional Komputer dan Sistem Intelijen. (KOMMIT) ISSN : 14116286, 2008.

[5] M. Naylor. "The Use of Mobile Agents in Network Management", MSc Information Technology (Systems Integration), 2000.

[6] P. Dasgupta, N. Narasimhan, L.E. Moser and P.M. Melliar-Smith, "MAgNET: Mobile Agents for Networked Electronic Trading", IEEE TRANSACTIONS ON KNOWLEDGE AND DATA ENGINEERING, Vol. 11, No. 4, 1999.

[7] Purbasari, Intan Yuniar and, Joko Lianto, "Rancang Bangun Perangkat Lunak Agent untuk Polling Halaman Web pada Selancar Web dalam Komunitas Menggunakan Aglet". Jurnal Teknologi Informasi dan Komunikasi, vol. 2 no. 1, pp. 15-21. ISSN 1978-0087, 2006. 
